\title{
Optimal oxygen titration in patients with chronic obstructive pulmonary disease: A role for automated oxygen delivery?
}

\author{
François Lellouche MD PhD¹, Jed Lipes MD FRCPC², Erwan L'Her MD PhD³
}

F Lellouche, J Lipes, E L'Her. Optimal oxygen titration in patients with chronic obstructive pulmonary disease: A role for automated oxygen delivery? Can Respir J 2013;20(4):259-261.

Oxygen therapy can be life-saving for patients with chronic obstructive pulmonary disease (COPD) and is the backbone of any acute COPD treatment strategy. Although largely considered to be a benign drug, many publications have highlighted the need to accurately adjust oxygen delivery to avoid both hypoxemia and the problem of hyperoxia-induced hypercapnia. Recent clinical data have shown that the deleterious effects of excess oxygen treatment can not only alter carbon dioxide levels (which has been known for more than 60 years) but can also lead to an increase in mortality. Nevertheless, despite the extensive literature, the risks associated with hyperoxia are often overlooked and published clinical recommendations are largely ignored. This failure in knowledge translation has become increasingly important not only because of the desire to reduce medical error, but in a society with limited health care resources, the economic burden of COPD is such that it cannot afford to make preventable medical mistakes. Recently, novel devices have been developed to automatically adjust oxygen flow rates to maintain stable oxygen saturations. These closed-loop oxygen delivery systems have the potential to reduce medical error, improve morbidity and mortality, and reduce health care costs. Preliminary data in this field are promising and will require a significant amount of research in the coming years to determine the precise indications for these systems. The importance of appropriate oxygen dosing and the current literature regarding novel oxygen delivery systems are reviewed.

Key Words: Closed-loop systems; Complications; COPD; Hypercapniainduced hyperoxia; Hyperoxia; Knowledge transfer; Oxygen therapy

Deleterious effects of hyperoxia in patients with chronic obstructive pulmonary disease (COPD) are often overlooked despite abundant literature regarding the subject (1). Recently, novel closedloop oxygen delivery systems have been developed with the potential to optimize oxygen titration and reduce complications associated with oxygen therapy (2).

\section{METHODOLOGY}

A literature search and review for the most significant articles regarding hyperoxia-induced hypercapnia were conducted (3-8). Past and present evidence are discussed, including a recent randomized controlled trial demonstrating the impact of hyperoxia in patients with acute respiratory failure on mortality in the prehospital setting (9). Preliminary data regarding new devices that automatically titrate oxygen flow to maintain constant oxygen saturation $(2,10-12)$ are also reviewed.

\section{OXYGEN THERAPY IN COPD:}

\section{A FAILURE IN KNOWLEDGE TRANSFER}

Risks associated with both hypoxemia and hyperoxia have been well described and, consequently, accurate adjustment of oxygen flow rates in COPD patients is of particular importance. However, to date, due to

\author{
Ajustement des débits d'oxygène chez les patients atteints \\ de maladie pulmonaire obstructive chronique. Un rôle \\ pour les systèmes automatisés d'oxygénothérapie?
}

L'oxygénothérapie diminue la mortalité chez les patients atteints de maladie pulmonaire obstructive chronique et il est un des traitements clé au cours des exacerbations aigues. Bien que largement considéré comme étant un traitement inoffensif, de nombreuses publications ont souligné la nécessité d'ajuster avec précision l'apport d'oxygène pour éviter à la fois l'hypoxémie et le problème de l'hypercapnie induite par l'hyperoxie. Des données cliniques récentes ont montré que l'excès d'oxygène peut augmenter les niveaux de dioxyde de carbone (ce qui est connu depuis plus de 60 ans), mais peut aussi conduire à une augmentation de la mortalité. Pourtant, en dépit de l'abondante littérature, les risques associés à l'hyperoxie sont souvent négligés et les recommandations cliniques publiées sont largement ignorées. Cet échec dans le transfert des connaissances est devenu de plus en plus problématique, non seulement en raison de la volonté de réduire les erreurs médicales, mais également au plan économique. Dans un système de santé sous pression, le fardeau économique de la maladie pulmonaire obstructive chronique est tel que nous ne pouvons nous permettre de faire des erreurs médicales évitables. Récemment, de nouveaux dispositifs ont été mis au point pour ajuster automatiquement les débits d'oxygène pour maintenir la saturation en oxygène stable. Ces systèmes automatisés de l'ajustement de l'oxygène ont le potentiel de réduire les erreurs médicales, d'améliorer la morbidité, la mortalité et pourrait réduire les coûts de la santé. Les données préliminaires dans ce domaine sont prometteuses mais nécessiteront de nouvelles recherches afin de déterminer les indications précises pour ces systèmes. Nous passerons en revue l'importance du dosage d'oxygène appropriée ainsi que la littérature émergente entourant les nouveaux systèmes d'administration d'oxygène.

limited advancements in technology as well as slow knowledge transfer, this goal remains elusive. The risks of hyperoxia, especially induced hypercapnia, although known since 1949 (6), are often overlooked; Beasley et al (1), however, have recently sounded the alarm bell. The first recommendations to adjust oxygen supply were published in 1967 by Campbell (4). Several medical societies have issued similar recommendations $(5,7)$; however, these recommendations are often not followed $(13,14)$. Reasons are likely multifactorial and are due, at least in part, to an underappreciation of the problem, especially in emergent situations and during prehospital transport. The recent demonstration in a large randomized controlled trial of excess mortality due to overoxygenation during prehospital transport (9) has revived the discussion regarding the potential harm of oxygen therapy (1).

\section{CLINICAL IMPACT OF EXCESSIVE OXYGENATION DURING EXACERBATIONS OF COPD}

Oxygen therapy is the most frequently administered emergency treatment in hospital and during prehospital care (7). The adverse effects of hyperoxia are well known in patients with COPD and are particularly marked during exacerbations $(3,8)$ (Figure 1). Plant et al (8) assessed the frequency and impact of respiratory acidosis in $983 \mathrm{COPD}$ patients admitted to the emergency department. Respiratory acidosis

${ }^{1}$ Centre de recherche de l'Institut Universitaire de Cardiologie et de Pneumologie de Quebec, Université Laval, Quebec; ${ }^{2}$ Adult Critical Care,

Jewish General Hospital, McGill University, Montreal, Quebec; ${ }^{3} \mathrm{CHU}$ de Brest, Hôpital de la Cavale Blanche, Brest, France

Correspondence: Dr François Lellouche, Centre de Recherche de l'Institut Universitaire de Cardiologie et de Pneumologie de Quebec,

2725 Chemin Sainte Foy, Quebec, Quebec G1V 4G5. Telephone 418-656-8711, fax 418-656-4509, e-mail francois.lellouche@criucpq.ulaval.ca 


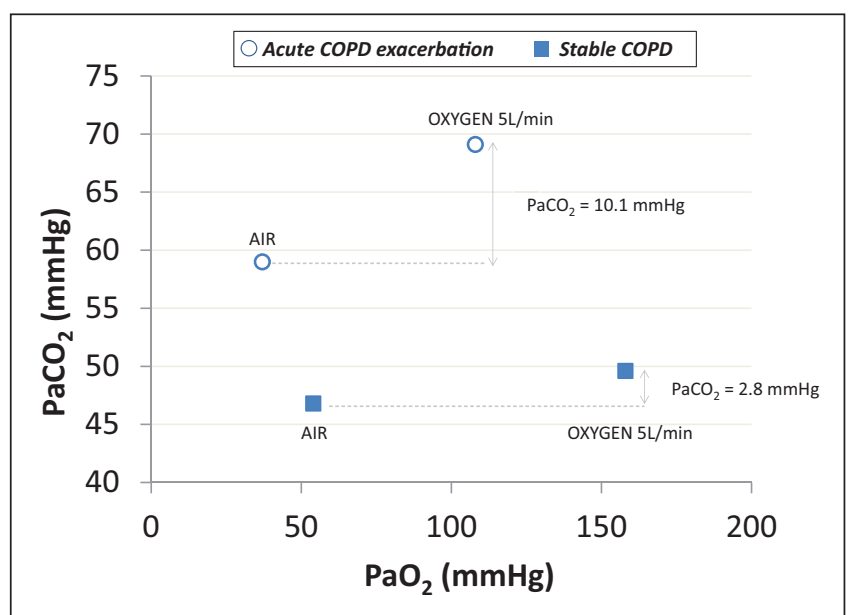

Figure 1) Impact of $30 \mathrm{~min}$ of oxygen at $5 \mathrm{~L} / \mathrm{min}$ on the average values of partial pressure of carbon dioxide $\left(\mathrm{PaCO}_{2}\right)$ in 12 patients with chronic obstructive pulmonary disease (COPD) studied at steady state (solid squares) and during exacerbation (open circles). Hypercapnia induced by hyperoxia was significantly higher during acute exacerbations. Adapted from reference 3

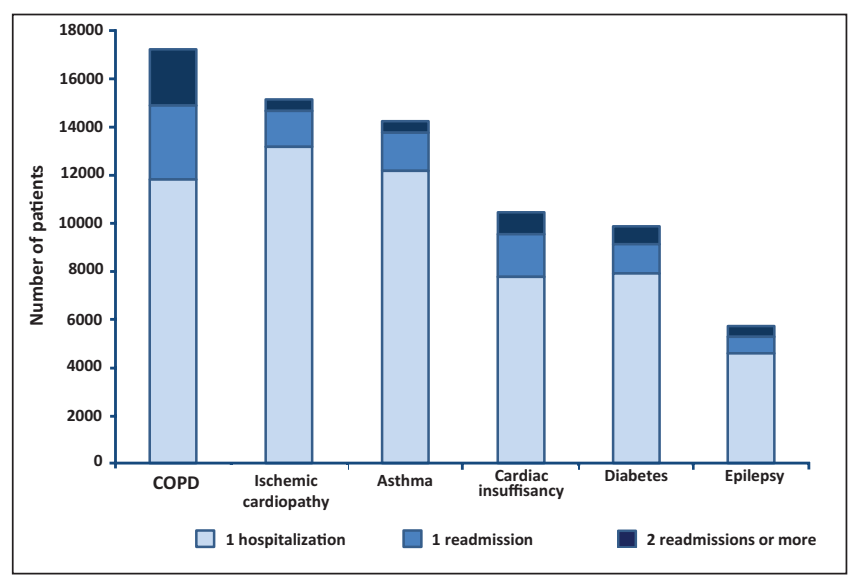

Figure 2) Annual hospitalizations and readmissions for major chronic diseases according to data from the Canadian Institute for Health Information (16). COPD Chronic obstructive pulmonary disease

on arrival was present in $20 \%$ of patients and was strongly correlated with the partial pressure of arterial oxygen, and significantly increased the risk of hospital death (6.9\% versus $12.1 \%$ in patients without versus with respiratory acidosis). More recently, in a large randomized controlled study, Austin et al (9) demonstrated that excess oxygen treatment increases mortality in COPD patients. In that study, 405 patients with an exacerbation of confirmed or presumed COPD were treated in ambulances with either high-flow oxygen $(8 \mathrm{~L} / \mathrm{min}$ to $10 \mathrm{~L} / \mathrm{min}$ ) or with oxygen flows adjusted to target an oxygen saturation $\left(\mathrm{SpO}_{2}\right)$ of between $88 \%$ and $92 \%$. The mortality rate was significantly reduced in patients with confirmed COPD treated with adjusted oxygen flows $(9 \%$ in the high-flow arm versus $2 \%$ in the adjusted-flow arm; $P=0.04)(9)$. Given the effects of hyperoxia on morbidity and mortality in COPD patients $(8,9)$, failure to comply with the recommendations to accurately adjust oxygen flow in patients with COPD could result in avoidable medical complications and significant added costs for the health care system.

\section{ECONOMIC BURDEN OF ACUTE EXACERBATIONS OF COPD}

Changing clinical practice in response to research data, known as knowledge translation, is difficult in many areas of medicine, resulting in excess morbidity and mortality and significant additional financial cost (15). This additional cost is difficult to quantify but is related to

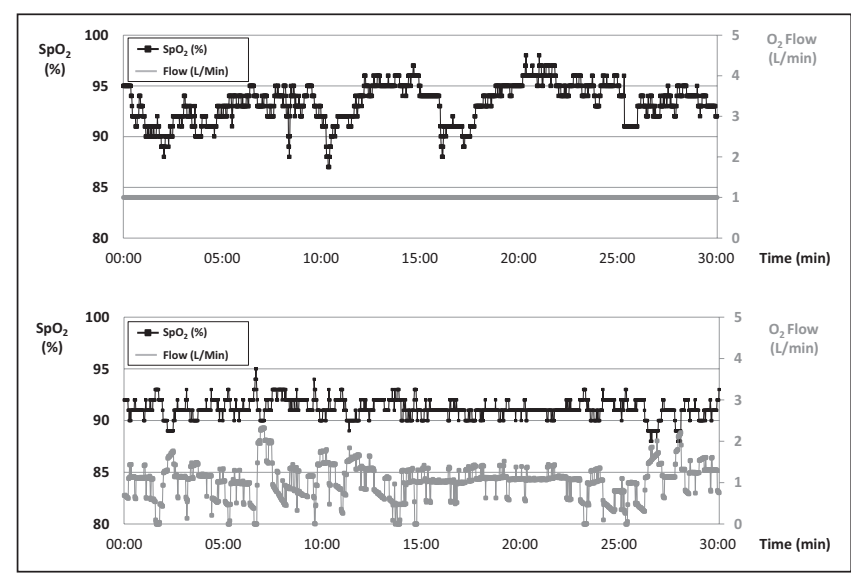

Figure 3) Typical variations at rest, of oxygenation (oxygen saturation $\left[\mathrm{SpO}_{2}\right]$ tracing in black) and oxygen flow (in gray) in a chronic obstructive pulmonary disease patient hospitalized for an exacerbation. Oxygen is delivered with constant flow (upper panel) and with a closed-loop system set to maintain an $\mathrm{SpO}_{2}$ at $91 \%$ (lower panel). $\mathrm{SpO}_{2}$ data are provided every second and are not filtered

the incidence of noncompliance with current guidelines and proportional to the prevalence of the disease. Recent statistical data regarding hospitalizations in Canada from the Canadian Institute for Health Information show that COPD is now associated with the highest rate of hospitalization among the major chronic diseases in Canada (16) (Figure 2). The total cost of COPD exacerbations is expected to exceed $\$ 1$ billion dollars annually by 2015 (17). Considering the economic burden of COPD, the strict control of oxygen flow rates should not be considered a minor problem. Thus, treatments that can be easily modified to limit morbidity and mortality have the potential for significant cost savings.

\section{FACILITATED KNOWLEDGE TRANSLATION VIA AUTOMATED OXYGEN THERAPY}

With regard to oxygen therapy, despite more than 50 years of research, transfer of knowledge to clinical practice to adequately adjust oxygen levels and minimize oxygen toxicity has been a failure (1). Current practice requires manual adjustments of oxygen flow rates via 'oxygen flowmeters'. The first report describing the use of an oxygen flowmeter was published in 1910 (18) and, since then, few innovations have occurred in the field of oxygen therapy. However, technological improvements have now allowed the use of more sophisticated devices to titrate oxygen therapy. One possible modern solution to facilitate knowledge transfer is to automate repetitive and relatively simple medical tasks. The adjustment of oxygen via a closed-loop system is promising. In such systems, the main parameter taken into account is $\mathrm{SpO}_{2}$, which continuously feeds the algorithm. A proportional integral controller adjusts the oxygen flow within a range (that differs from one device to another), with the aim of maintaining the $\mathrm{SpO}_{2}$ within a predefined target that can be set by the clinician. Three systems that attempt to achieve this goal have recently been developed $(2,10-12)$ (Figures 3 and 4); however, only preliminary data are available.

In one study, the authors evaluated a closed-loop system (O2 Flow Regulator, Dima, Italy), adjusting oxygen during exercise in COPD patients while receiving long-term oxygen therapy (10). The mean ( \pm SD) $\mathrm{SpO}_{2}$ was $95 \pm 2 \%$ with automated adjustment and $93 \pm 3 \%$ with manual adjustment $(\mathrm{P}=0.04)$. A reduction in the respiratory therapists' workload was documented with automated adjustment compared with manual adjustment $(2.0 \pm 0.1 \mathrm{~min}$ versus $5.6 \pm 3.7 \mathrm{~min}$; $\mathrm{P}=0.005)$. In another study with a similar device $($ AccuO2, Optisat Medical, USA) set to target a $\mathrm{SpO}_{2}$ of $90 \%$, the mean $\mathrm{SpO}_{2}$ was significantly different $(90.7 \pm 1.9 \%$ versus $92.4 \pm 3.6 \%$ versus $92.2 \pm 4.4 \%)$ compared with traditional systems of oxygen delivery (12). In 
addition, this system allowed for a reduction in oxygen consumption. The $\mathrm{FreeO}_{2}$ device (Oxynov, Canada) was validated in a preliminary study involving healthy volunteers under conditions of moderate hypoxemia (11) and in COPD patients during exercise.

These systems have the potential to decrease health care costs by minimizing the risks of hyperoxia and associated complications caused by the inadvertent administration of high-flow oxygen. In addition, these systems allow for automated oxygen weaning and remote monitoring, which may facilitate early hospital discharge following exacerbations of COPD. Such strategies have the potential to substantially decrease the related health care costs given that hospitalizations represent the main cost associated with severe exacerbations of COPD (17).

\section{RECOMMENDATIONS FOR CLINICAL PRACTICE AND FUTURE RESEARCH}

Oxygen therapy can be life-saving; however, too much of a good thing can be harmful. Given the accumulation of recent data, clinicians should titrate oxygen therapy to avoid both hypoxia and hyperoxia. Modern oxygen delivery systems may help achieve accurate oxygen delivery in the future. The potential benefits of automated oxygen titration may exist for both patients (better control of oxygenation, better monitoring) and for the health care system (reduced workload, improved monitoring with fewer adverse events, better compliance with recommendations, reduced oxygen use and early hospital discharge following exacerbations of COPD). However, additional data are required to demonstrate the safety of these systems in different settings (prehospital transportation, emergency, hospital and home care) and cost/benefits of such systems should be adequately demonstrated.

\section{REFERENCES}

1. Beasley R, Patel M, Perrin K, O'Driscoll BR. High-concentration oxygen therapy in COPD. Lancet 2011;378:969-70.

2. Claure N, Bancalari E. Automated closed loop control of inspired oxygen concentration. Respir Care 2013;58:151-61.

3. Aubier M, Murciano D, Fournier M, Milic-Emili J, Pariente R, Derenne JP. Central respiratory drive in acute respiratory failure of patients with chronic obstructive pulmonary disease. Am Rev Respir Dis 1980;122:191-9.

4. Campbell EJ. The J. Burns Amberson Lecture. The management of acute respiratory failure in chronic bronchitis and emphysema. Am Rev Respir Dis 1967;96:626-39.

5. Celli BR, MacNee W. Standards for the diagnosis and treatment of patients with COPD: A summary of the ATS/ERS position paper. Eur Respir J 2004;23:932-46.

6. Davies CE, Mackinnon J. Neurological effects of oxygen in chronic cor pulmonale. Lancet 1949;2:883-5.

7. O'Driscoll BR, Howard LS, Davison AG. BTS guideline for emergency oxygen use in adult patients. Thorax 2008;(63 Suppl 6):vi1-68.

8. Plant PK, Owen JL, Elliott MW. One year period prevalence study of respiratory acidosis in acute exacerbations of COPD: Implications for the provision of non-invasive ventilation and oxygen administration. Thorax 2000;55:550-4.

9. Austin MA, Wills KE, Blizzard L, Walters EH, Wood-Baker R. Effect of high flow oxygen on mortality in chronic obstructive pulmonary disease patients in prehospital setting: randomised controlled trial. BMJ 2010;341:c5462.

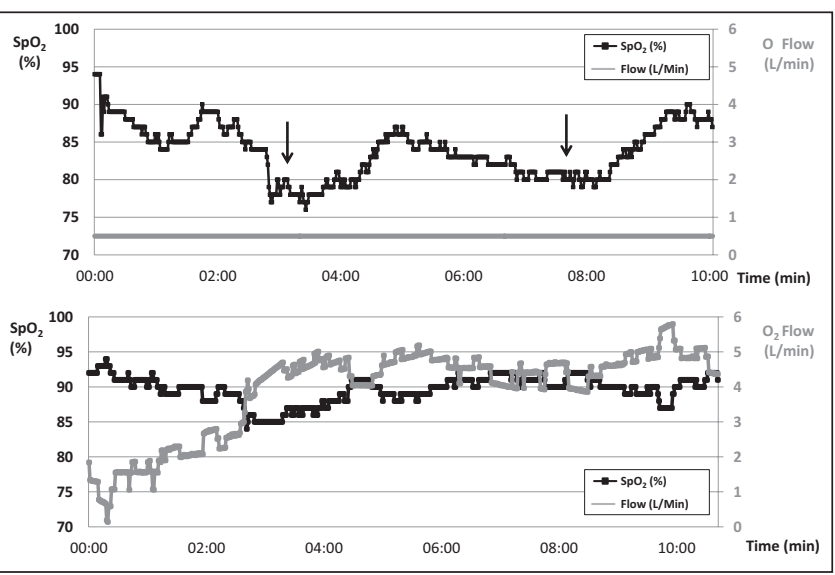

Figure 4) Typical variations during exercise, of oxygenation (oxygen saturation $\left[\mathrm{SpO}_{2}\right]$ tracing in black) and oxygen flow (in gray) in a chronic obstructive pulmonary disease patient hospitalized for an exacerbation. Oxygen is delivered with constant flow (upper panel) and with a closed-loop system set to maintain an $\mathrm{SpO}_{2}$ at $91 \%$ (lower panel). $\mathrm{SpO}_{2}$ data are provided every second and are not filtered. With constant oxygen flow, the patient was required to stop exercising twice (arrows)

DISCLOSURES: Dr Erwan L'Her and Dr François Lellouche developed one of the automated oxygen delivery systems discussed in this review and have founded a society (Oxynov, Canada) with the aim of commercializing the device.

10. Cirio S, Nava S. Pilot study of a new device to titrate oxygen flow in hypoxic patients on long-term oxygen therapy. Respir Care 2011;56:429-34.

11. Lellouche F, L'Her E. Automated oxygen flow titration to maintain constant oxygenation. Respir Care. 2012;57:1254-62.

12. Rice KL, Schmidt MF, Buan JS, Lebahn F, Schwarzock TK. A portable, closed-loop oxygen conserving device for stable COPD patients: Comparison with fixed dose delivery systems. Respir Care 2011;56:1901-5.

13. Hale KE, Gavin C, O'Driscoll BR. Audit of oxygen use in emergency ambulances and in a hospital emergency department. Emerg Med J 2008;25:773-6.

14. Wijesinghe M, Perrin K, Healy B, et al. Pre-hospital oxygen therapy in acute exacerbations of chronic obstructive pulmonary disease. Intern Med J 2011;41:618-22.

15. McGlynn EA, Asch SM, Adams J, et al. The quality of health care delivered to adults in the United States. N Engl J Med 2003;348:2635-45.

16. Institut canadien d'information sur la santé. Indicateurs de santé 2008. <http://secure.cihi.ca/cihiweb/products/Healthindicators2008_ FRweb.pdf $>$

17. Mittmann N, Kuramoto L, Seung SJ, Haddon JM, Bradley-Kennedy C, Fitzgerald JM. The cost of moderate and severe COPD exacerbations to the Canadian healthcare system. Respir Med 2008;102:413-21.

18. Neu M. Ein Verfahren zur Stickoxydulsauerstoffnarkose. Munch Med Wochenschr 1910;57:1873-5. 


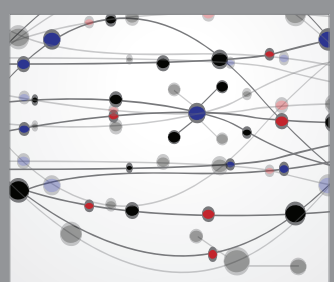

The Scientific World Journal
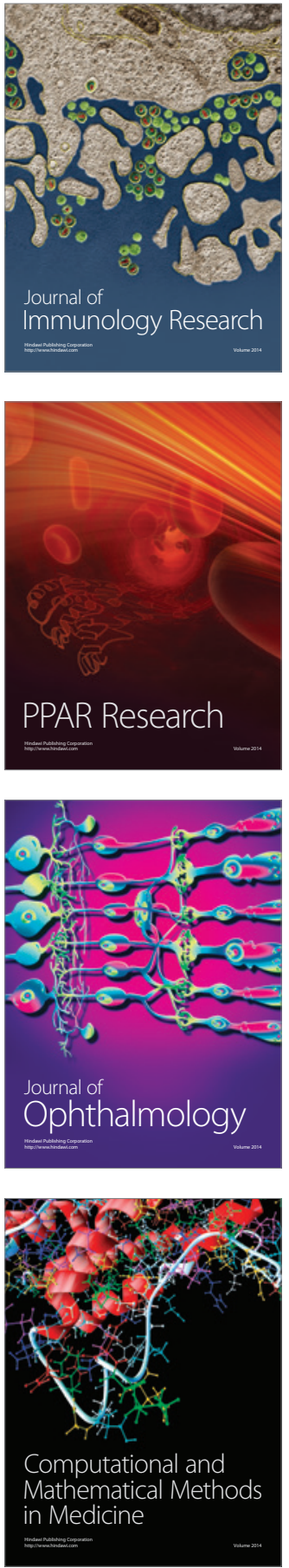

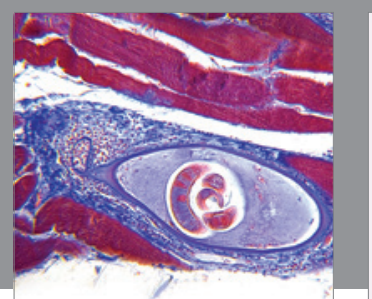

Gastroenterology Research and Practice

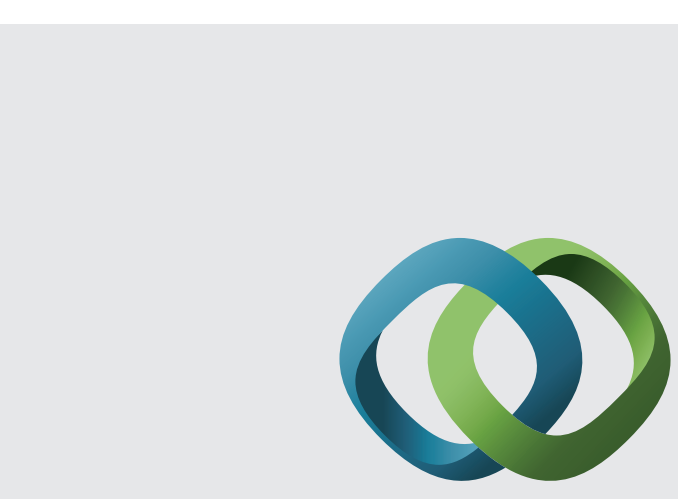

\section{Hindawi}

Submit your manuscripts at

http://www.hindawi.com
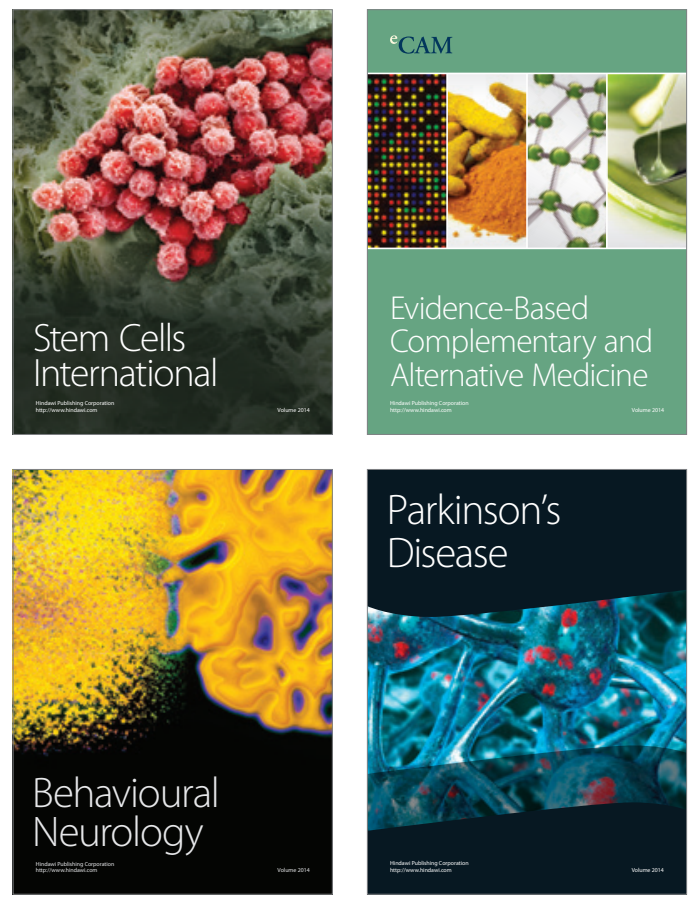
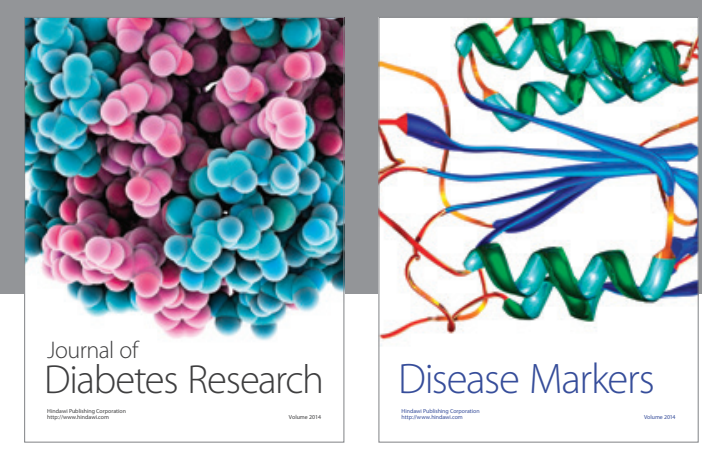

Disease Markers
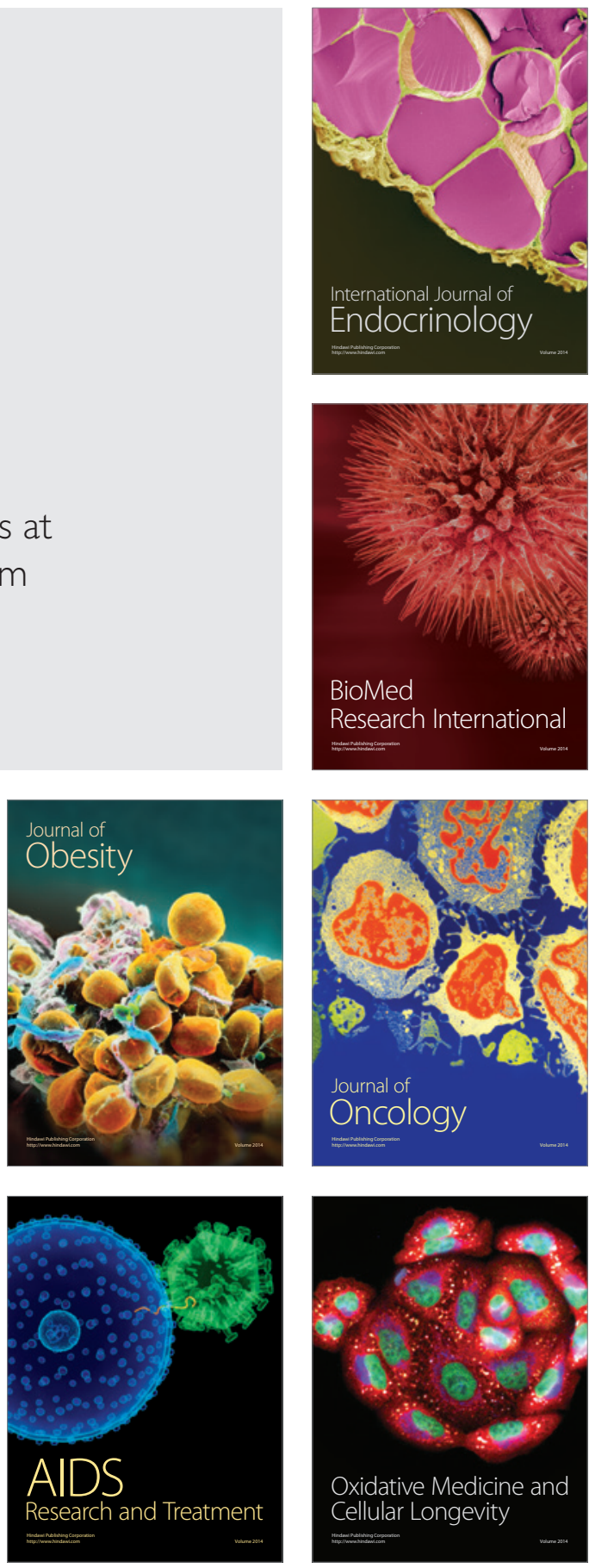